\title{
PALAVRA PATRIMÔNIO: NARRATIVAS ORAIS NO ASSENTAMENTO ROSE
}

EDIL SILVA COSTA

https:/ /orcid.org/0000-0001-5327-3502

Universidade do Estado da Bahia

EDISVÂNIO DO NASCIMENTO PEREIRA

https://orcid.org/0000-0002-6680-0858

Universidade do Estado da Bahia

RESUMO As comunidades tradicionais possuem formas de transmissão de saberes predominantemente orais, ancoradas em vínculos parentais e afetivos fundamentais para sua existência e preservação. Com uma organização social complexa e cadeia hierárquica baseada na antiguidade do saber, demonstram força e vitalidade na atuação de mestres reconhecidos pelo grupo social. Os mais velhos exercem uma liderança natural no grupo e se destacam como guardiões dos saberes que estruturam os modos de vida coletivo. Trataremos da comunidade narrativa do Assentamento Rose, uma comunidade de sem terras localizada no município de Santa Luz, Bahia. Trata-se de uma comunidade diaspórica, cujos sujeitos são oriundos de várias cidades, se reorganizando em torno de interesses comuns. Os aspectos culturais são de extrema importância para a reorganização dos sujeitos em comunidade e, por isso, nosso interesse nas narrativas orais e contos populares presentes no Assentamento, a partir da atuação do narrador Zé de Souza. Será analisado o conto "O homem preguiçoso", discutindo as relações de trabalho e de poder encontradas na narrativa. Desse modo, veremos como as narrativas tradicionais, no seu processo de transmissão e continuidade, carregam muito da personalidade do narrador, mas, acima de tudo, documentam as formas de organização social da comunidade, ainda que de forma indireta, e preservam, reafirmam e fortalecem valores estruturantes para o grupo social.

Palavras-chave: Conto popular. Assentamento. Cultura. Trabalho. Preguiça. 
ABSTRACT WORD HERITAGE: ORAL NARRATIVES IN THE

\section{ASSENTAMENTO ROSE}

Traditional communities have predominantly oral forms of knowledge transmission, anchored in parental and affective bonds that are fundamental for their existence and preservation. With a complex social organization and hierarchical chain based on the age of knowledge, they demonstrate strength and vitality in the performance of masters recognized by the social group. The elders exercise a natural leadership in the group and stand out as guardians of the knowledge that structures the collective ways of life. We will deal with the narrative community of Assentamento Rose, a landless community located in the municipality of Santa Luz, Bahia. It is a diasporic community whose subjects come from various cities, reorganizing themselves around common interests. Cultural aspects are extremely important for the reorganization of the subjects in community. That is why our interest in oral narratives and folktales present in the Settlement, based on the performance of the narrator Zé de Souza. The short story "O homem preguiçoso" (the lazy man) will be analyzed, discussing the working and power relations found in the narrative. In this way, we will see how traditional narratives, in their process of transmission and continuity, carry much of the narrator's personality, but above all document the forms of social organization of the community, albeit indirectly, and preserve, reaffirm and strengthen values. structuring factors for the social group.

Keyword: Popular tale. Settlement. Culture. Work. Laziness.

\section{RESUMEN PALABRA PATRIMONIO: NARRATIVAS ORALES EN EL ASSENTAMENTO ROSE}

Las comunidades tradicionales tienen formas predominantemente orales de transmisión del conocimiento, ancladas en vínculos parentales y afectivos que son fundamentales para su existencia y preservación. Con una organización social compleja y una cadena jerárquica basada en la edad del conocimiento, demuestran fortaleza y vitalidad en el desempeño de los maestros reconocidos por el grupo social. Los ancianos ejercen un liderazgo natural en el grupo y se destacan como guardianes del conocimiento que estructura las formas de vida colectivas. Nos ocuparemos de la comunidad narrativa del Assentamento Rose, una comunidad sin tierra ubicada en el municipio de Santa Luz, Bahia. Es una comunidad diaspórica cuyos sujetos provienen de varias ciudades, reorganizándose en torno a intereses comunes. Los aspectos culturales son extremadamente 
importantes para la reorganización de los temas en la comunidad. Es por eso que nuestro interés en las narraciones orales y los cuentos populares presentes en el Acuerdo, basados en la actuación del narrador Zé de Souza. El cuento "O homem preguiçoso" (el hombre perezoso) será analizado, discutiendo las relaciones laborales y de poder que se encuentran en la narrativa. De esta manera, veremos cómo las narrativas tradicionales, en su proceso de transmisión y continuidad, llevan gran parte de la personalidad del narrador, pero sobre todo documentan las formas de organización social de la comunidad, aunque indirectamente, y preservan, reafirman y fortalecen los valores. factores estructurantes para el grupo social.

Palabras clave: Cuento popular. Asentamiento. Cultura. Trabajo. Pereza.

\section{Palavras iniciais: as narrativas orais como patrimônio}

As narrativas orais são um importante aspecto do patrimônio imaterial de uma comunidade, uma vez que narrar um acontecimento, um conto popular ou histórias de vida pode revelar, no contexto coletivo, as organizações sociais do grupo; e no contexto mais familiar ou restrito, a construção de uma narrativa que exteriorize o que o sujeito quer tornar público, uma imagem construída de si e seu modo de ver o mundo. Dessa forma, as narrativas podem documentar crenças, valores ou preconceitos que dão luz ao conhecimento sobre o outro e sobre nós mesmos.

São consideradas narrativas orais tradicionais as que nos remetem a um passado longínquo, embora permaneçam atuais. Desse modo, estão na memória da comunidade que as repetem e atualizam continuamente. Mesmo quando a narrativa não é da tradição oral, em comunidades narrativas, as formas de narrar são tradicionais e os modos de transmissão do saber calcados na oralidade mantêm fortes vínculos com o passado e a ancestralidade.

A memória dos acontecimentos próprios do grupo fortalece seus vínculos de identidades que são laços vitais para sua coesão. Para o sujeito, narrar sua história é dizer quem é, é construir o passado no qual se sustenta o presente e propulsiona o devir. Assim também é com um grupo social cuja narrativa é construída para dar existência a si próprio e aos demais. Em última instância, narrar é existir. 0 que não foi narrado não existe no meio social.

Nas comunidades tradicionais, cujas formas de transmissão de saberes e fazeres são predominantemente orais, os vínculos humanos, parentais e afetivos são fundamentais para sua existência e preservação. São comunidades cuja organização social é muito complexa e sofisticada, com cadeia hierárquica baseada na antiguidade do saber, no respeito a uma história que poderia parecer frágil aos sujeitos de sociedades predominantemente letradas, mas que demonstra sua força e vitalidade na atuação de líderes e mestres reconhecidos pelo grupo social onde atuam. Os mais velhos e aqueles que exercem uma liderança natural no grupo se destacam como sustentáculos da vida comunitária e guardiões dos saberes que estruturam os modos de vida coletivo. Guardiões no sentido de preservar, não deter, pois eles sabem que a melhor forma de preservar é 
passar adiante o que sabem, com o cuidado de repetir de modo fiel e adequado. A repetição prepara a nova geração para a continuidade, embora seja inevitável e necessária a atualização das informações. Estudar as comunidades tradicionais requer atenção e cuidado às formas sofisticadas de organização social que as estruturam, evitando o julgamento de valor e a análise a partir de parâmetros externos. A pesquisa é, portanto, um exercício de alteridade.

Nesse artigo trataremos da comunidade narrativa chamada de Assentamento Rose, uma comunidade de sem terras localizada no município de Santa Luz, região do Semiárido da Bahia'. Um aspecto peculiar desse agrupamento humano é o fato de, como em muitos assentamentos no Brasil, se formar a partir de sujeitos oriundos de diversas partes, com interesses e modos de vida semelhantes. Tratase de uma comunidade diaspórica que vai se reorganizando em torno de alguns elementos que ganham coesão e se fortalecem à medida que a estrutura do acampamento melhor se organiza. Uma liderança ou algumas lideranças consolidadas fazem muita diferença nesses grupos. Os aspectos culturais comuns também.

Nosso olhar se volta para as narrativas orais e o conto popular presentes no Assentamento Rose, a partir da atuação do narrador José Dantas de Ataídes, conhecido por Zé de Souza. Analisaremos o conto que ele intitula "O homem preguiçoso", propondo discutir, do ponto de vista formal, a composição do texto e sua recepção; do ponto de vista temático, as relações de trabalho e poder, situando a narrativa em seu contexto de produção. Desse modo, veremos como as narrativas tradicionais, no seu processo de transmissão e continuidade, carregam muito da personalidade do narrador, mas, acima de tudo, documentam as

1 Para informações mais detalhadas sobre o Assentamento Rose, consultar a pesquisa de Pereira (2018). formas de organização social da comunidade, ainda que de maneira indireta, preservando, reafirmando e fortalecendo valores estruturantes para o grupo social.

\section{O Assentamento Rose: território, pessoas, culturas}

Segundo dados do IBGE de 2019², o município de Santa Luz, distante 258 km de Salvador, tem uma área territorial de 1.560 km², com população estimada de 37.348 habitantes. A uma distância de $6 \mathrm{~km}$ da sede de Santa Luz está o Assentamento Rose, território de articulações, mobilizações e resistência.

O cordelista e escritor Nelci Lima da Cruz relata que existem duas versões sobre a história da fundação do município de Santa Luz. A primeira diz que aconteceu "[...] em 1880, onde é hoje a Estação Ferroviária; e teria sido fundada pelo Senhor José Lopes" (CRUZ, 1996, p. 20). De outra parte, o mesmo autor aponta uma segunda versão, dizendo que em 1850 já existiam alguns moradores na Fazenda Morro dos Lopes, também fundada pela família Lopes (CRUZ, 1996, p. 25). Entretanto, apesar da divergência, conserva-se como data de fundação o ano de 1880 porque foi a partir dele que teve início a Vila de Santa Luzia, hoje cidade de Santa Luz. O marco é a inauguração da estrada de ferro que ligava a estação de São Francisco, em Alagoinhas, ao Rio São Francisco, em Jua-

2 Santa Luz está localizada na região Planejamento Nordeste do Estado da Bahia, limitando-se a leste com os municípios de Araci e Conceição do Coité, a sul com Valente, São Domingos e Gavião, a oeste com São José do Jacuípe e Queimadas; e a norte com Nordestina e Cansanção. A economia do município está baseada na agricultura familiar, criação de caprinos e no comércio varejista, além de ser reconhecida na Bahia e no Brasil por sua produção de sisal e extração de pedras e minerais como ouro, ferro e magnésio. Disponivel em: http://cidades.ibge.gov.br/xtras/perfil. php?lang=\&codmun=292800\&search=bahia|santaluz. Acesso em: 28 abr. 2017. 
zeiro da Bahia. A estação de São Francisco foi aberta entre 1880 e 1896, pelo Governo brasileiro ${ }^{3}$, mudando consideravelmente a vida das comunidades da região.

Embora historicamente prevaleça no Brasil, como organização de maior atuação nos processos de ocupações de terras, o Movimento dos Trabalhadores Sem Terra (MST), é importante ressaltar que o Assentamento Rose não foi articulado e ocupado por esta organização. Isto não significa dizer que ele não tenha relações de afinidade com o movimento. Pelo contrário, uma de suas fontes de inspiração é o MST, obviamente, seguindo as orientações das Organizações da Sociedade Civil do Território do Sisal e seus parceiros. No entanto, a formação do Assentamento aconteceu como resultado da presença de diversas instituições, sindicatos de trabalhadores rurais, associações comunitárias e demais organizações da sociedade civil.

O surgimento do Projeto de Assentamento (PA) Lagoa do Boi, conforme descreve o filho de assentado Gilson Santiago ${ }^{4}$, nasceu na noite de 10 de julho de 1989. Os assentados passaram a chamar o PA Lagoa do Boi de Rose, ou Comunidade Rose, logo após a ocupação, em homenagem à líder camponesa Roseli Celeste Nunes da Silva, que morreu num conflito de terras, no início do MST, na década de 80 , no Rio Grande do Sul.

A terra do Assentamento Rose foi ocupada depois de várias reuniões de planejamentos e estratégias, quando famílias dos municípios de Conceição do Coité, Retirolândia, São Domingos e Valente, apoiadas por sindicatos dos

3 Informações disponiveis em: http:// www.estacoesferroviarias.com.br/ba_paulistana/santaluz.htm. Acesso em: 05 maio 2017.

4 Graduado em Letras Vernáculas pela Universidade do Estado da Bahia, através do Programa Nacional de Educação na Reforma Agrária - PRONERA. Informações sobre o Rose disponíveis no blog da APOCOR -Associação de Pequenos Agricultores da Comunidade Rose. Disponivel em: http://apacor.blogspot.com. br/p/historia-do-rose.html. Acesso em: 10 abr. 2017. trabalhadores rurais de Retirolândia, Valente e São Domingos, juntamente com a Paróquia de Conceição do Coité e a Associação de Desenvolvimento Sustentável e Solidário da Região Sisaleira/BA $(A P A E B)^{5}$ de Valente, decidiram ocupar a Fazenda Lagoa do Boi, que naquela época pertencia à Companhia de Celulose da Bahia (CCB). Hoje, conforme dados do Instituto Nacional de Colonização e Reforma Agrária (INCRA), o Rose conta com uma área de 1.360 hectares de terra e possui 78 posseiros ${ }^{6}$.

Durante o período de ocupação, os assentados do Rose tiveram que enfrentar condições precárias em meio a frio, sol, chuva, poeira, lama, tendo que passar por muitas ocasiões da hora de comer, morando debaixo de um barraco de lona e pindoba de ouricurizeiro?, com dois metros quadrados, dormindo em camas feitas de flecha de sisal, forradas com capim-açu ${ }^{8}$ (o colchão construído por eles). Por

5 A sigla APAEB se refere a princípio à Associação de Pequenos Agricultores do Estado da Bahia, atuante também nos municípios de Araci, Serrinha e Ichu. Em Valente, a sigla permaneceu usada para representar a Associação de Desenvolvimento Sustentável e Solidário da Região Sisaleira/BA.

6 Há dois conceitos que definem o termo: 1) posseiro é a pessoa que tem, na prática, a posse de uma porção de terra, mas não é dono na lei, não possui documentação, nem registro em cartório. Já o conceito 2 , diz que posseiros são lavradores que, juntamente com a família, ocupam pequenas áreas de terras devolutas ou improdutivas, isto é, terras que não estão sendo utilizadas e que pertencem ao governo. Disponivel em: http://apacor.blogspot.com.br/p/historia-do-rose.html. Acesso em: 10 fev. 2017.

7 Ouricurizeiro, também conhecido como palmeira sertaneja, que pode atingir até 11 metros de altura. 0 licuri (nome cientifico: Syagrus coronata) é também chamado por alicuri, aricui, adicuri, cabeçudo, coqueiro-aracuri, coqueiro-adicuri, iricuri, oricuri, uricuri, e uricuriba. Suas folhas são utilizadas na fabricação artesanal de sacolas, chapéus, vassouras, espanadores, entre outros. A espécie pode ser encontrada no norte de Minas Gerais, na porção oriental e central da Bahia até o sul de Pernambuco e nos estados de Alagoas e Sergipe. Disponivel em: www.embrapa.br. Acesso em: 03 abr. 2017.

8 O capim-açu (Andropogon minarum), também conhecido como capim canutão e capim doido, é uma erva que cresce até um metro de altura e pertence à família das gramíneas, nativa do Brasil e presente do Estado do Maranhão até o estado de São Paulo. Tal espécie possui folhas lineares e inflorescências bem densas. Além de fornecer forragem, suas sementes 
muitas vezes, também enfrentaram a falta de atendimento às necessidades básicas ao ser humano e, além disso, viveram o drama de enfrentar o medo de possiveis ataques de fazendeiros e seus capangas?.

Como é bastante sabido, o Brasil é um país que, ao longo de sua história, tem sido marcado por diversos conflitos. No que diz respeito à concentração de riquezas, a grosso modo, temos de um lado as forças das elites, do capitalismo, dos latifundiários e dos políticos que em suas tentativas de permanecerem a todo custo no exercício do poder, matam, excluem, marginalizam e violam, de todas as formas, os direitos humanos. É neste "cabo de guerra" que, do outro lado, concentram-se as classes trabalhadoras, perseguidas e marginalizadas. Estas classes têm buscado, ao longo da história, sair da condição de assujeitados, de subalternos, de marginalizados, para, a partir das suas lutas, darem novos sentidos e significados às suas histórias de vida. Sendo assim, a tentativa destes sujeitos é a de deixarem a condição de subalternos para se tornarem protagonistas. Em certa medida, essa é a sua forma:

[...] de luta e seus modos de enunciação são singulares e respondem a uma dobra do poder, como acontecimento: confronta o chefe local, expõe representantes do sistema de poder (a cada instância que interpela e supera em sua vontade de justiça), mobiliza seus parcos recursos de camponeses pobres... [...] ativa sua sensibilidade e inteligência, à medida em que os desafios vão se colocando durante seu processo de luta e enfrentamento. (SANTOS, 2016, p. 61)

\section{O Brasil detém o maior índice de concen-}

são diuréticas. Disponível em: www.embrapa.br. Acesso em: 03 abr. 2017.

9 O uso do termo 'capanga' se aplica aqui ao sujeito que recebia dinheiro de fazendeiros, empresários e/ou políticos para lhes servirem de guarda-costas e fiéis escudeiros, sendo, inclusive, capazes de armar emboscadas e matar para atender aos desejos dos seus "chefes". tração de terras do mundo. Como consequência dos grandes latifúndios, temos também o maior número de pessoas que não possuem terra para produzir. É neste mesmo Brasil que há a prevalência de terras improdutivas, com marcas históricas que mergulham no tempo e remontam ao começo da invasão portuguesa e todo o período em que prevaleceu o sistema escravagista. Dessa maneira, no que se refere à busca por igualdade e acesso à terra, os processos de luta e resistência ocorrem desde a invasão portuguesa, como nos lembra Fernandes (2000, p. 25):

[...] começou com a chegada do colonizador europeu, há 500 anos, desde quando os povos indígenas resistem ao genocídio histórico. Começaram, então, as lutas contra o cativeiro, contra a exploração, e, por conseguinte, contra o cativeiro da terra, contra a exploração, contra a expulsão e contra a exclusão, que marcam a história dos trabalhadores desde a luta dos escravos, da luta dos imigrantes, da formação das lutas camponesas. Lutas e guerras, uma após a outra, ou ao mesmo tempo, sem cessar, no enfrentamento constante contra o capitalismo.

Se, por um lado, o Brasil é marcado historicamente por falta de políticas públicas e investimentos que possibilitem condições de igualdade para todas as classes sociais, por outro, desde o início da colonização, há as marcas de um povo que persiste, resiste e luta por direitos e para não ser mais "invisível" aos olhos de uma sociedade onde prevalece o poderio político e econômico reacionário. É nesse cenário de resistência que situamos o Assentamento Rose.

É necessário esclarecermos que há uma diferença entre os conceitos de "acampamento" e "assentamento": o primeiro, é considerado como um instrumento de luta fundamental pela conquista da terra. Segundo Caldart (2004), os acampamentos podem ser considerados como cidades de "barracos de lona", para se referir ao material e ao tipo de habita- 
ção utilizados para a realização do movimento. Ainda segundo a mesma autora, os acampamentos são construídos na área pretendida para transformá-la posteriormente em assentamento; ou margeando rodovias, nas partes externas das fazendas. Sendo que cada acampamento, entretanto, possui estratégias diferentes de sobrevivência e resistência. Mas o objetivo é sempre o mesmo, ou seja, tornar explícita a luta, pressionar o governo e mobilizar a opinião pública a respeito da questão da terra.

O acampamento é organizado e constituído a partir da participação da comunidade e de reflexões, por meio de instâncias coletivas que realizam assembleias e fazem as deliberações. Além disso, possuem as instâncias participativas que se encarregam da gestão do trabalho. São os chamados "coletivos" que assumem as funções de tratar de assuntos que visam ao desenvolvimento de ações que mantenham ativamente o funcionamento do grupo, abordando vários pontos cruciais para a manutenção deste, como: mobilização, educação, atividades culturais, saúde, segurança, dentre outros.

Neste sentido, Stedile argumenta que “[...] todas as instâncias do Movimento, desde as comissões de base, dentro de um acampamento, até as instâncias nacionais, são exercidas coletivamente, na forma de colegiado, sem distinção de poder" (1997, p. 104). Por fim, o acampamento nada mais é que o ato reivindicatório e o instrumento de mobilização, enfrentamento, pressão e resistência para alcançar o objetivo destes coletivos, que é o acesso à terra. Sem o processo de ocupação e acampamento, indubitavelmente, não haveria assentamento.

Já o "Assentamento", que é o pós-acampamento, segundo Caume (2002) e Medeiros (2003), pode ser considerado como a principal resposta do Estado brasileiro às pressões e mobilizações dos movimentos sociais em todo o território nacional que lutam por reforma agrária. Dessa forma, constitui-se aí o que pode ser entendido como uma tentativa de intervenção do Estado sobre um conflito social.

Nesta perspectiva, conforme Caldart (2004), pode-se considerar que o assentamento, neste instante, passa a ser um espaço de luta diferente do acampamento, visto que o assentamento indica que a terra já é uma "conquista" e, daí por diante, passa a ser organizada uma nova comunidade. Neste sentido, o assentamento é o momento em que há a desapropriação da terra de um determinado latifúndio pelo Estado brasileiro, dando posse aos sujeitos que lutaram por esta conquista. A partir deste momento, a terra está legalizada e seus assentados não podem mais sofrer interferências nem serem retirados, a não ser que parem de produzir. É importante ressaltar que é feita a divisão da terra em partes iguais aos assentados (posseiros), e, após este momento, as famílias adquirem o direito de trabalhar, produzir, acessar crédito do governo e construir suas moradias.

o quadro brevemente apresentado nos mostra que a vida nos assentamentos não é fácil. Além das atividades na lavoura, os trabalhadores vivem em meio às tensões, temendo possiveis represálias dos fazendeiros ou embates com os poderes públicos. Porém, mesmo dedicados às labutas diárias, ainda é possivel cultivar o tempo do lazer e das reuniões festivas. Nesses intervalos, conseguem se reunir ao redor de uma fogueira e ali, desfrutando o calor do fogo e o contato humano, fazem das noites frias momentos aquecidos de alegria com cantigas, poesia, contação de contos e causos, samba de roda, reisado e cantoria.

É nesse contexto que encontramos Zé de Souza. Como foi dito, nos limites desse artigo trataremos do conto "O homem preguiçoso", narrado por ele. A escuta atenta dessa narrativa nos permite refletir sobre as formas tra- 
dicionais de narrar, mas também sobre questões relacionadas ao patrimônio imaterial do Assentamento Rose, em particular, e as formas de organizações sociais de grupos populares, em geral.

\section{"O homem preguiçoso": conexões da vida com a arte da palavra}

José Dantas de Ataídes, ou simplesmente Zé de Souza, como gosta de ser chamado, já que, segundo ele, esse é seu nome artístico, hoje tem 76 anos. De estatura mediana, se classifica como de pele morena. Possui os cabelos grisalhos, por circunstâncias de suas mais de sete décadas de vida. Como parte dos senhores sertanejos, seus contemporâneos, mantém sempre o hábito de usar o bigode por fazer. É natural do município de Valente e pai de 12 filhos. Reside em Rose desde a ocupação e sempre se dedicou à labuta de trabalhar na roça, no ofício de agricultor. Um mestre contador de causos e contos populares, intérprete, tocador de violão, cantador de reisado, samba e, como bem diz ele, "muitas outras coisas da música e da arte, pois sua vida é uma arte".

Zé de Souza é integrante dos projetos culturais do assentamento, exercendo o papel de instruir crianças, jovens e adultos com aulas de violão e contação de contos populares e causos. Possui um modo bem peculiar de narrar, conduzindo a narrativa com naturalidade, descontração e leveza. Dentre as peculiaridades do mestre está a capacidade de surpreender, inserindo uma narrativa tradicional no meio de uma conversa sobre qualquer tema. Essa estratégia, que permite ao narrador conduzir o ouvinte, transitando do mundo real ao ficcional e vice-versa, nos revela como o sujeito estampa as marcas de sua vivência nas narrativas, nos levando do plano simbólico para o político e promovendo o trânsito do estético para o ético.
Considerando essa premissa, a narrativa "O homem preguiçoso" nos esclarece a respeito de muitos discursos construídos historicamente. Assim como reservas indigenas e remanescentes de quilombos, as áreas de assentamento de reforma agrária são marcadas por serem constituídas por pessoas excluídas das políticas sociais, econômicas e educacionais. Logo, são também pessoas marginalizadas, tidas como miseráveis ou mesmo "ladrões de terras"; e ainda carregam o estereótipo de "vagabundos, baderneiros e preguiçosos".

Esse discurso carregado de ódio e preconceitos chega a ser tão violento e bárbaro quanto a ausência de tais políticas e é produzido e reproduzido, diuturnamente, justamente pela elite brasileira, que tem como aliada grande parte da mídia televisiva, radiofônica e impressa que, historicamente, age de forma tendenciosa, reacionária e falsamente moralista. Por conta disso, muitas vezes essas ideias são tomadas e repetidas também por parte da classe média ou mesmo por muitos que vivem em estado de pobreza.

Se por um lado há adversidades, por outro pode-se constatar a construção de estratégias de resistência que promovem movimentos e articulações, como é exemplo as ações resultantes em organizações como o Assentamento Rose. Por seu turno, os discursos hegemônicos a respeito dos movimentos sociais tendem a ser depreciativos e estereotipados porque reconhecer virtudes como a capacidade de resistência e organização por parte das comunidades populares é também mostrar o fracasso do modelo institucional que, hierarquizando, exclui e marginaliza. Está claro que essas ações de resistência são incômodas e podem provocar reações, pois: "Os poderosos temem as virtudes, porque elas têm o poder de provocar a resistência contra a dominação e contagiar aqueles que devem derrubar suas estruturas" (BOGO, 2009, p. 41). 
Zé de Souza é um cidadão pouco letrado, se considerarmos a educação formal, assim como muitos senhores e senhoras residentes no Assentamento, tendo em vista que não tiveram acesso à escola em suas respectivas épocas pela escassez de estabelecimentos escolares públicos. Além disso, tiveram que se dedicar ao trabalho da roça, desde muito jovens, para ajudar às suas famílias. Logo, não conseguiram concluir o Ensino Médio, um curso profissionalizante ou Superior. Todavia, é importante observar que essa realidade não se aplica mais para os jovens filhos e filhas dos assentados, visto que este cenário tem se modificado. Hoje já é possível perceber que muitos conseguiram concluir o Ensino Médio, Técnico e mesmo curso Superior.

No caso de Zé de Souza, pode-se observar que a falta de oportunidade de acesso aos estudos não se tornou fator que o limitasse. Com seu talento, o mestre narrador proporciona ao ouvinte uma imersão no universo ficcional e simbólico. Através das vozes poéticas e seus significantes, da palavra e da escuta, ouvintes, aprendizes e brincantes tornam-se protagonistas que interagem com o mestre.

Os narradores são detentores de um vasto conhecimento oral e o domínio sobre a linguagem verbal e corporal que utilizam para a transmissão do saber e manutenção da memória coletiva. Seguindo a perspectiva de Bosi, em sua obra Memória e Sociedade: lembrança de velhos (2001), o instrumento capaz de socializar a memória é a linguagem; e isso ocorre independentemente de como ela se apresenta. Ainda segundo esta mesma autora, "As convenções verbais produzidas em sociedade constituem um quadro ao mesmo tempo mais elementar e mais estável da memória coletiva" (BOSI, 2001, p. 56). Desse modo, ao propormos deferência e atenção ao mestre Zé de Souza, que é detentor de um repertório excepcional que abarca causos, contos populares, lendas locais e regionais, busca-se reconhecer, através de suas habilidades, assim como de outros tantos mestres e mestras do Rose, o quanto ele contribui para que as atividades culturais da comunidade continuem sendo desenvolvidas e ganhem visibilidade para além do Rose.

\section{A narrativa se apresenta}

O homem preguiçoso ${ }^{10}$

Aconteceu em um povoado, onde morava o jovem Mané, juntamente com seus familiares. 0 rapaz era muito bonito, de altura média, gordo e de pele morena clara. Mané durante toda sua vida, não sabia o que era trabalhar. Se casou e permaneceu nessa vidinha. Desde muito tempo era só comer e deitar na rede olhando o dia e o tempo passarem! Por ser um rapaz bonito, sua esposa Mariinha, não se importava em fazer tudo e trabalhava duro na lida da roça para alimentar seus filhos e suprir todas as necessidades da família. Mané era tão preguiçoso, que malmente se levantava da rede, fazia suas refeições ali mesmo. Até as forças que ele tinha para ir até o quarto dormir, com o tempo se esgotaram. Havia mais de dois anos, que ele não dormia com sua mulher! Moravam numa casinha que, em meio à escuridão, só se via as luzes do candeeiro saindo pelas brechas das janelas e portas e pelos buracos do telhado... Lá estava Mané, bem assossegado, esparramado na rede ao lado do fogo de lenha, olhando as faíscas subirem pelo telhado.

De repente se assustou com as batidas fortes na porta e, ao ver que não havia ninguém mais para atender, por medo foi abrir a porta. Ele se levantou lentamente, bem devagar, xingando e foi abrir pra ver quem era o condenado que estava na porta naquele horário. Ao abrir, o susto foi maior ainda! Em sua frente estava um homem de cara não agradável, com um saco enorme nas costas. Trazia em si, um ar assustador, este homem bem-disposto foi logo falando:

10 Versão adaptada a partir da narrativa de Zé de Souza, de modo a dar mais fluidez à leitura. Foram retiradas as repetições e hesitações características da narração oral, porém mantidos os traços mais peculiares da narrativa. 
- Boa noite, meu senhor! Você pode me deixar entrar, para assar uns pequenos pedaços de carne no seu fogão?

Mané ainda trêmulo disse:

- Boa noite. Entre. Fique à vontade!

A presença deste homem deixava Mané sem ação. $O$ ar ficava pesado, que chegava a lhe sufocar. Atrás da porta da cozinha, estava o seu filho Joaquim, que escutava e assistia àquela cena que the apavorava. 0 homem logo se aproximou do fogo, colocou o saco no chão e desamarrou; tirou um braço bem gordo e enfiou no espeto, colocou-o para assar, virou o espeto de um lado para o outro e, antes de assar, ele o devorou em três mordidas. Não se saciando, puxou uma coxa que estava pingando de gordura e passou na brasa rapidamente. A sua fome era tanta, que não tinha paciência de esperar, comia com uma vontade, que se lambuzava, mordia a carne grosseiramente, que os dentes trincavam no osso. Ao terminar, chupou o osso, lambeu as mãos e os dedos. Mané vendo aquilo se apavorava. Os seus olhos ficavam para cair no chão de tão arregalados. Ele se benzia a todo o momento, resmungava baixinho:

- Meu Deus! Que monstro é esse?

O homem, depois de se limpar, olhou para Mané de cima a baixo, vendo aqueles braços e coxas roliços, ele perguntou:

- Hei! Você sabe onde posso encontrar algum preguiçoso para eu fazer um lanche?

Mané deu um pinote da rede falando assustado, forte e seguro:

- Não sei não senhor! Por aqui não há preguiçoso! Falando nisso, com licença, que eu vou cuidar de minha vida.

Mané desceu para o quintal, onde tinha vários pés de gameleiras. Chegando lá, agarrou a enxada e travou na labuta. De longe, se avistava a poeira e os matos subirem. Ao amanhecer, Mariinha mandou o filho Joaquim ir levar o café de Mané na rede. 0 menino logo respondeu:

- Pai, não está na rede não, mãe.

A senhora, retruca perguntando ao filho:
- E aonde ele está? Se não for naquela rede?

- Pai está no quintal, capinando, mãe. - Respondeu ele tranquilamente.

A senhora deu uma risada irônica e mandou o garoto ir chamar Mané para tomar café. Já eram aproximadamente umas sete horas e Joaquim, como era um bom menino, obedeceu à sua mãe e foi chamar seu pai. Ao chegar lá, falou:

- Pai, mãe disse para o senhor ir tomar café.

O pai do garoto, ainda assombrado perguntou:

- Ô meu filho! Aquele homem, ainda está lá em casa?

- Está, pai. Está lá na beira do fogo.

- Ave Maria! Misericórdia! Diga a tua mãe que mais logo eu vou. - Replicou ele, com ar de medo.

E assim fez o garoto. Quando deu meio-dia, Mariinha mandou o menino ir chamar Mané novamente.

- Ô meu pai, minha mãe disse para o senhor ir almoçar. - Disse o menino Joaquim, como se nada estivesse acontecendo.

- E o homem? Ainda está lá? Está, meu filho?

- Perguntou Mané, ansiosamente, imaginando que o homem tivesse ido embora.

- Está sim, meu pai. Por que o senhor pergunta tanto sobre este homem assombroso?

- Por nada não, meu filho! Diga à sua mãe que não estou com fome ainda.

Mariinha achava aquilo estranho, mas, no entanto, não procuraria se interessar pela aquela indiferença que the intrigava. Já era tarde demais e nada de Mané voltar pra casa. Lá pelas três horas da tarde, Joaquim é mandado por sua mãe ir de novo chamar seu pai. Lá se foi o menino dar o recado.

- Pai, mãe disse que pelo amor de Deus! É para o senhor ir comer.

- ô, meu filho!

- Diga para seu pai, o homem já foi? Ele já saiu de casa? 
Perguntou Mané, com ar de súplica.

- Já, pai. Ele se foi.

- Graças a Deus! Agora já posso ir! - Respondeu ele com enorme sensação de alívio.

Encostou a enxada em uma árvore e foi para casa. Ao se aproximar da porta, olhou assustado de lado, percebendo que o homem já tinha ido embora, se sentiu mais aliviado e pôde entrar em sua casa. A esposa vendo o seu marido suado e de camisa tirada, com o corpo empoeirado, ela acabou acreditando no que o filho tinha falado anteriormente. Mané, se sentindo um trabalhador, pediu uma toalha para ir tomar um banho. Logo após, se sentou à mesa para almoçar. Ele passou o resto da tarde proseando com a mulher.

A noite caiu e chegou a hora de todos se recolherem para os seus leitos. Mané ficou sozinho, inquieto na sala, pensando no homem que havia lhe assustado a noite passada. Ficava olhando para todos os lados e cantos da casa. Pensava de ir até o quarto de sua esposa, mas se sentia sem jeito de se aproximar. 0 medo que the tirava o sono e o sossego. Mas com vergonha, foi para o quarto de sua esposa. Chegando lá, a mulher perguntou:

- O que você quer, Mané? O que está acontecendo?

O homem, sem jeito, falou timidamente:

- Nada não, benzinho! Ô mulher, me deixe dormir hoje com você!

Mariinha, que estava carente, aceitou com muito prazer.

- Vem, meu lindo! Pode deitar! - Disse Mariinha, a senhora entusiasmada.

Deste dia por diante, Mané se tornou um homem trabalhador e passou a ter amor mais à vida e à sua esposa, seus filhos e ao trabalho. Ficar contando as horas do dia preguiçosamente na rede? Quem disse? Nunca mais!

O conto "O homem preguiçoso" é um conto de exemplo e uma variante de narrativas com o tema da preguiça espalhadas pela tra- dição oral do mundo todo (COSTA, 2015)11. Nas coletâneas de contos populares portugueses (CASCUDO, s. d.), há registros de inúmeras versões. Nas coletâneas brasileiras também encontramos a narrativa comumente intitulada "João Preguiçoso" (CASCUDO, 2004). É comum no repertório de nossos narradores na Bahia (ALCOFORADO; ALBÁN, 2001). O tema da preguiça, tanto no homem como na mulher, é sempre motivo de riso, crítica e castigo. Considerada como um dos pecados capitais, a preguiça deve ser rechaçada e o preguiçoso redimido.

A versão de Zé de Souza é bastante detaIhada. Na primeira sequência narrativa, ele faz uma contextualização dos personagens, descreve as características físicas de Mané e Mariinha, exaltando as qualidades da mulher trabalhadora e "chefe da família", responsável pelo sustento da casa. Note-se que não há interesse em descrever a aparência da mulher, já que suas qualidades são morais e não físicas. Ao contrário, é importante dizer da boa aparência do homem, além de seu desvio moral. Assim, o narrador traça um perfil dos personagens de modo a contrastá-los: a mulher é corajosa, trabalhadora, capaz de sustentar a casa, enquanto o esposo é um rapaz "muito bonito, de altura média, gordo e de pele morena clara" que, apesar de muito forte e de todo o vigor físico, vive "bem assossegado, esparramado na rede ao lado do fogo de lenha, olhando as faíscas subirem pelo telhado".

A rede é um elemento chave convertido em símbolo de preguiça. É importante lembrar que um dos objetos que surpreendeu os europeus no processo de colonização do Brasil foi o modo de dormir dos nativos, "pendurados

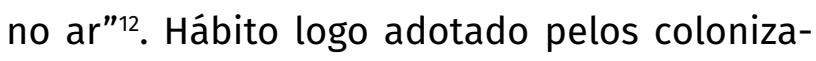

11 Em outras versões, a narrativa pode ser configurar como um conto religiosos do Ciclo de Jesus e São Pedro pelo mundo, havendo a interferência de Jesus Cristo, que é quem aparece disfarçado de andarilho com Pedro e finge-se de antropófago para assustar o preguiçoso, provocando sua mudança de atitude.

12 Para um estudo detalhado sobre a preguiça na cultu- 
dores, foi tomado como exemplo de um modo de vida indolente, de pouco trabalho. Ainda hoje a rede é associada a descanso, lazer e férias, haja vista os folhetos de propaganda turísticas que vendem o litoral nordestino como lugar paradisíaco. Assim como a rede é uma imagem constante para a publicidade turística, é também presença constante nos contos populares com o tema da preguiça. Diferente da cama para dormir, onde o trabalhador merecidamente descansa de sua labuta, a rede é vista como um lugar de folga constante, para contemplação, horas a fio, daqueles que não conseguem sequer chegar ao quarto, como é o caso do Mané do conto em questão.

Sabemos que, embora em comunidades tradicionais haja uma divisão de trabalho bastante rígida, com os papeis sociais bem definidos a partir das relações de gênero, as mulheres costumam trabalhar nas roças, além de cuidarem da casa e dos filhos. Assim, não seria de se estranhar a conduta de Mariinha. Porém, a atitude de Mané é inadequada, tanto que o narrador procura justificar a aceitação da mulher pela beleza do marido. A primeira sequência da narrativa é, portanto, a contextualização. 0 narrador expõe os fatos e constrói uma situação de desequilíbrio que irá se desenrolar ao longo do conto e se resolver ao final. Sendo uma narrativa exemplar - ou um conto de exemplo, como classifica Luís da Câmara Cascudo (2004) - o texto carrega uma moral a ser explicitada: a má conduta deverá ser corrigida e a boa conduta recompensada. Os dois personagens representam esses dois lados da moeda. O filho Joaquim é um personagem que intermedia os dois (note-se que até o menino trabalha, pois é ele quem leva as refeições e os recados para o pai).

$\mathrm{Na}$ primeira sequência narrativa, as coisas pareciam acomodadas antes da chegada do

ra brasileira ver Ensaios de Malandragem e preguiça (COSTA, 2015). forasteiro. É ele quem desencadeia o desequilíbrio da frágil e aparente harmonia do casal. 0 forasteiro revela-se um canibal e não se trata de um canibalismo qualquer: o sujeito é seletivo na sua alimentação, escolhendo comer preguiçosos, assustando Mané ao perguntar onde poderia encontrar um preguiçoso para "fazer um lanche". Sua presença fratura a narrativa iniciando a sequência decisiva para a mudança de atitude do preguiçoso.

O conto poderia acabar aí, mas o narrador prolonga a história explorando o aspecto assustador do canibalismo, descrevendo o ato de devorar partes de um corpo humano com detalhes grotescos. 0 medo do preguiçoso fica evidente nessa sequência:

Ao terminar, chupou o osso, lambeu as mãos e os dedos. Mané vendo aquilo se apavorava. Os seus olhos ficavam para cair no chão de tão arregalados. Ele se benzia a todo o momento, resmungava baixinho:

- Meu Deus! Que monstro é esse?

Ao fugir para a roça, ele pergunta três vezes ao filho se o "homem assombroso" já foi embora. A repetição é típica dos contos populares, em geral três vezes. Trata-se de uma estratégia para prolongar a ação dos personagens e o deleite da narrativa, mas também para facilitar a memorização, assim como a assimilação dos ensinamentos. Mané, ao perguntar ao filho se o homem já teria ido embora, demonstra reiteradas vezes o medo que o canibal despertou nele. O filho, por sua vez, por três vezes, transmite à mãe a recusa de Mané em voltar para casa e testemunha o estranhamento dela, o que também reforça a ideia de que a atitude do marido é contrária ao esperado. A demora em retornar da roça dá ao preguiçoso a oportunidade de remissão. 0 tom cômico dado à história revela a crítica que a sociedade faz às atitudes de Mané, mas também a condescendência para com ele, talvez por empatia, talvez 
por rebeldia, uma vez que as relações de trabalho no Brasil foram e ainda são, em grande parte, calcadas na lógica de exploração do outro.

Se pensarmos no cotidiano do narrador e dos demais moradores do Rose e de como essa narrativa tem a ver com os modos de vida da comunidade, facilmente poderíamos pensar que o personagem Mané não seria bem visto em um grupo em que o trabalho é necessário e obrigatório. Mas não buscamos uma leitura fácil nem desse conto nem das narrativas construídas pelas diversas vozes presentes no grupo.

Ao criar esse cenário narrativo traçando os perfis dos dois personagens, o mestre Zé de Souza nos convida a uma imersão no imaginário, nos instigando a pensar a respeito de que tipo de relação poderíamos fazer com a comunidade Rose e mesmo a partir de quais aspectos seria possivel estabelecermos alguma relação. Se a partir do conto seria possivel pensarmos nos modos de fazer e produzir dos assentados, tanto no âmbito cultural, quanto na busca dos projetos e, assim, fazer a captação de recursos que possibilitem o desenvolvimento social, cultural e econômico da comunidade.

Nesta perspectiva, podemos observar que estas inquietações nos aproximam do que pensa Zumthor (2005) ao se referir ao momento em que o texto se transforma em voz, pelo narrador, em seu momento de performance. Para este autor:

[...] na hora em que, em performance, o texto [...] se transforma em voz, uma mutação global afeta suas capacidades significantes, modifica o seu estatuto semiótico e gera novas regras de semanticidade. 0 tempo que continua a audição e que dura a presença, o gesto e a voz colaboram (necessariamente) com o texto para compor o sentido. (ZUMTHOR, 2005, p. 148)

As colocações de Zumthor nos levam a pensar que o narrar é coletivo. Quem narra, narra para alguém e os ouvintes compartilham da narrativa, aprovando ou desaprovando as condutas dos personagens. 0 que fortalece ou garante a permanência de um tema ou outro em uma tradição é a relação com o contexto e as relações deste com os modos de vida de um grupo social (COSTA, 2015, p. 7-8). Considerando a aprovação da voz do narrador e o resultado apresentado no conto, pode-se dizer que a comunidade não só corrobora com os valores ali expressos como irá colaborar para seu fortalecimento.

Podemos também observar que o conto reflete a realidade social do narrador e do público ouvinte. Ainda no início da narrativa, quando Zé de Souza descreve a casa onde morava Mané com a esposa e filho, a descrição é claramente a de uma casa sertaneja, perfeitamente de acordo com os costumes rurais e da região. O fogão de lenha é um exemplo, assim como a rede já citada. Estas características, trazidas pelo mestre Zé de Souza, mostram o seu sentimento de pertencimento ao seu lugar, à sua história de vida, vida de sertanejo que também vivera em uma casa semelhante.

Portanto, o narrador compõe seu texto a partir dos elementos de sua realidade social, deixando marcas individuais e coletivas. Quanto a isso, pode-se fazer uma analogia a partir do pensamento da pesquisadora Jerusa Pires Ferreira, na medida em que ela considera que a tradição oral opera como "[...] uma espécie de reserva conceitual, icônica, metafórica, lexical, e sintática, que carrega a memória dos homens, sempre pronta a se repetir e a se transformar num movimento sem fim" (2017, p. 91). Seguindo esta mesma linha de raciocínio, Roland Barthes argumenta, afirmando que narrativa e indivíduo caminham sempre juntos, tendo em vista que "[...] não se pode haver narrativa sem narrador e sem ouvinte" (BARTHES, 1972, p. 47).

O narrador, ao trazer informações a respeito dos comportamentos tanto do perso- 
nagem Mané quanto do homem que batera à porta, traz um cenário envolvente que nos leva ao imaginário da cena. Primeiro, referese ao aborrecimento de Mané, por ninguém ter ido abrir a porta, tendo ele que obrigar-se a abri-la; em seguida, o susto que ele toma ao se deparar com um sujeito de aparência nada agradável e assustadora. Neste momento, percebe-se que o narrador traz para à cena narrativa jogos de efeitos e suspense a respeito do que poderia acontecer no decorrer da história, sobretudo porque ele nos faz imaginar que essa passagem do conto se dá à noite. Entra em cena, portanto, a performance do narrador que, segundo Zumthor (2010, p. 205), cada uma permite, a princípio, avaliar os poderes expressivos em jogo e a relação que estabelece entre eles.

Observa-se na narrativa o perfil do sertanejo, acolhedor, receptivo, que mesmo ao desconhecido tem o hábito de acolher em seu lar. No Assentamento Rose, seus moradores celebram com música a recepção dos seus visitantes. Assim eles cantam:

Sejam bem-vindos à nossa comunidade[...] Nós queremos abraçar, com muita categoria, quando vem traz alegria, quando vai, deixa saudades $[. . .]^{13}$

É importante ressaltar que, embora haja o sentimento de cordialidade de Mané, este mesmo sentimento se transforma em medo frente ao comportamento do seu "visitante". Nesta passagem do conto, o narrador envolve a sua plateia, construindo cenários que levam Mané de um homem assustado a um sujeito que evoca a sua fé, seu credo religioso e até clama por Deus. Mais uma vez, aqui o narrador nos põe à frente do seu contexto regional, na medida em que ele direciona o sujeito assustado ao encontro do Deus Cristão. Sendo assim, cada performance se torna singular,

13 Versos cantados pelos mestres da oralidade do Rose. estabelecendo, neste momento, um “[...] contexto ao mesmo tempo cultural e situacional. Não podem ser desligados do contexto, isto é, da pessoa que as interpreta e, sobretudo, da situação de vida e de convivência, em função das quais foram elaboradas e são executadas" (ZUMTHOR, 2010, p. 36).

Outro aspecto que merece observação é que o medo de Mané fez despertar a coragem para o trabalho, fazendo com que ele se levante da rede imediatamente e parta para o quintal para capinar. Isso acontece no instante em que o homem o indaga se por ali não haveria "algum preguiçoso para ele fazer um lanche".

Observa-se que a linguagem é muito peculiar e característica do dialeto local. A cultura se estrutura a partir da língua natural dos sujeitos e, desse modo, os contos podem ser um importante documento para estudos de variação linguística, a quem interessar. Para os estudos de poéticas orais, essas variações interessam do ponto de vista estético, pois notase que o emprego de uma palavra e não de outra, de uma expressão idiomática ou outra, vai interferir nos sentidos que a narrativa carrega. A literatura é a arte que se produz a partir de uma matéria- prima também utilizada no cotidiano com a função de comunicar. Ao trabalhar a arte da palavra, o poeta ou narrador lapida a linguagem de modo a retirá-la do seu uso cotidiano, criando novos sentidos e explorando ao máximo seu significante. Ou seja, considerando que a cultura se estrutura a partir das línguas naturais, além de trazer elementos da cultura local, os modos de vida de seu contexto, o narrador dá uma feição regional ao texto, antes de tudo, do ponto de vista da língua falada em cada lugar.

Desse modo é que notamos que o mestre usa expressões do falar de sua região. Para demonstrar a agilidade de Mané ao sair da rede, por exemplo, diz: "Mané deu um pinote da rede". "Dar um pinote" é empregado no 
sentido de levantar-se rápido, demonstrando agilidade. Ao usar essa expressão para a ação do "preguiçoso", o narrador está dizendo ao ouvinte que o homem é suficientemente ágil, forte e saudável. Que nada o impediria de trabalhar, exceto a preguiça ou a falta de vontade. Além disso, o uso de "dar um pinote" dará ao ouvinte uma ideia visual mais dinâmica do que uma expressão como "levantou-se rapidamente", por exemplo. "Pinote" é, a princípio, uma ação de animais cavalgadores, o que empresta à cena um ar cômico também.

$\mathrm{Na}$ passagem seguinte, Mané responde ao forasteiro: “- Por aqui não há preguiçoso! Falando nisso, com licença, que eu vou cuidar de minha vida". A expressão "cuidar na vida" também merece atenção. Pode ser analisada de duas formas: a primeira, a respeito de ir se dedicar ao trabalho, à lida do dia a dia. É um termo muito usado na região e no assentamento quando um sujeito se refere ao trabalho. Significa também, para estes sujeitos, que trabalhar está relacionado à questão de sobrevivência.

Por outro lado, o narrador ao se referir a "cuidar na vida", diz respeito ao que Mané também pensou naquele momento. Manterse vivo, já que, ao se deparar com um homem disposto a comer carne humana, sobretudo de pessoas que não gostam de trabalhar, a cena leva a crer que ele seria o próximo a ser devorado por aquele sujeito tão faminto. Assim, pode-se deduzir que:

Todos esses componentes, signos e sinalizadores do universo cultural do contador, são incorporados ao texto no momento da performance, imprimindo-lhe mais funcionalidade e significados narrativos para a comunidade receptora. (ALCOFORADO, 2008, p. 241)

O que a afirmação de Alcoforado nos faz crer é que existe a cumplicidade dos ouvintes para com o narrador e sua identificação com o texto narrado. Para isso se concretizar, o narrador deve falar do jeito que os ouvintes compreendem e reproduzam. Na performance, compartilha-se não só o texto, mas também o que ele veicula. A funcionalidade a que a autora se refere permite a permanência do conto na comunidade narrativa e tem a ver com o pacto que se estabelece com os receptores. A função das narrativas, a princípio, é divertir e ensinar, transmitir uma mensagem exemplar aos ouvintes, mas não traz nenhuma novidade. 0 final é o que se espera: castigo para os maus e recompensa para os bons. A repetição é o reforço dessas lições já sabidas pelos ouvintes.

O narrador nos conduz ao final do conto descrevendo a sensação de alivio de Mané quando, ao final da tarde, seu filho, Joaquim, lhe disse que o homem "assombroso" teria ido embora. O narrador se preocupa, ainda, em dar um desfecho para a história, tratando também da mudança de comportamento de Mané, tanto no que se refere ao trabalho, quanto na própria relação com Mariinha, tendo em vista que ele retornara a dormir com a esposa. Esta passagem narrada pelo mestre Zé de Souza, em certa medida, pode ser considerada como uma lição, no que se refere às circunstâncias da vida, indo, portanto, ao encontro do pensamento de Hampâté Bâ, já que este afirma:

O ensinamento não é sistemático, mas ligado às circunstâncias da vida. Este modo de proceder pode parecer caótico, mas, em verdade, é prático e muito vivo. A lição dada na ocasião de certo acontecimento ou experiência fica profundamente gravada na memória da criança. (HAMPÂTÉ BÂ, 1982, p. 192)

A este respeito, o conto narrado pelo mestre Zé de Souza nos faz acreditar que tal ensinamento, ratificado pelo autor supracitado, vai além do aprender das crianças, já que este se ocupa de contar para todos da comunidade que se dispõem a escutá-lo. Logo, no caso do Rose, as lições são passadas também para jo- 
vens e adultos, como é característico de uma comunidade narrativa que compartilha valores tradicionais.

\section{A palavra como patrimônio}

Como procurou-se mostrar a partir do narrador Zé de Souza, o Assentamento Rose possui um movimento de narradores que se ocupam do ofício de transmitir seus conhecimentos aos demais moradores da comunidade. Isso nos leva a pensar que a oralidade adquire um maior significado, ao passo que reconhecemos a elaboração da palavra como uma capacidade do ser humano que sempre precede à escrita, em qualquer lugar ou sociedade.

Elizeu Clementino de Souza fala sobre a narrativa, dizendo que ela "[...] abre espaços e possibilita aos sujeitos em processos de formação, partilhar experiências formadoras" (SOUZA, 2008, p. 85). Nesta perspectiva, as narrativas orais transmitem aos mais jovens não só conhecimento dos modos de ser e fazer tradicionais, mas as experiências dos sujeitos que podem formatar modelos a serem seguidos e preservados, experiências partilhadas por várias gerações, sustentadas na oralidade e em suas diversas formas de registro.

Neste contexto, as lideranças da comunidade Rose, articuladas com os moradores, conseguiram estabelecer parcerias com organizações não governamentais, fator que foi determinante para elaboração e implementação dos projetos culturais. As articulações com as instituições parceiras resultaram na formação de um acervo composto por desenhos, pinturas, roteiros de peças teatrais, xilogravuras, folhetos de cordel, gravações de áudios e livros. É importante ressaltar que o acervo não se configura apenas no armazenamento e na catalogação de textos ou produções culturais dos narradores do assentamento, pois considera-se que:
[...] o acervo se constitui como um lugar identitário, nele, por exemplo, pode se guardar a memória de um determinado autor, não somente seus livros, mas suas roupas, seus rascunhos e tudo que possa ser usado para reforçar a memória e facilitar as pesquisas. (BORDINI, 2005, p. 38)

Desse modo, a importância desse acervo está não só no registro, que informa a vontade de preservação de uma memória, mas também na capacidade de produzir novas memórias e novos significados. Locais de identidade onde, conforme explica Zumthor (1993), a comunidade constrói sua narrativa ampla e coletiva. Os narradores são, assim, "arquivos vivos" (COSTA, 2016, p. 60) e, no compartilhamento de suas poéticas orais e experiências, vão tecendo novos sentidos, de modo que

[...] os textos da poesia de audição se reagrupam na consciência da comunidade, em seu imaginário, em sua palavra, em conjuntos discursivos às vezes muito extensos, e em que cada elemento semantiza (segundo a cronologia das performances) [...] (ZUMTHOR, 1993, p. 47)

Assim, os narradores tecem também a vida. É importante ressaltar que em Rose é característica marcante a presença das narrativas orais, seja em rodas de conversa, em atividades culturais, ou em reuniões para discutir o desenvolvimento de projetos para a comunidade. Portanto, a narrativa oral nos aponta para uma perspectiva de que os saberes orais presentes e transmitidos pelos narradores do Rose possibilitam novos saberes e fazeres. Para compreendermos os sujeitos e seus valores, traçamos um movimento pendular, transitando nas idas e vindas da narrativa para a vida.

Se observarmos o conto narrado pelo mestre Zé de Souza, nele o narrador traz todo o enunciado narrativo da construção de um sujeito preguiçoso, "incapaz" de sair de sua rede para ir sequer buscar um copo de água 
para tomar. Este enunciado pode levar à interpretação de que os sujeitos da zona rural, entre eles os assentados, são acomodados, relapsos e preguiçosos. Entretanto, é oportuno que se diga que esta é a forma como se refere a eles parte da sociedade brasileira que criminaliza os movimentos de trabalhadores, em especial os sem terra. Por outro lado, sabemos que, ao contrário do que pode sugerir a narrativa do "João Preguiçoso", a vida de quem está nos acampamentos e, posteriormente, assentamentos, requer empenho, dedicação, articulação, mobilização, criatividade e muito trabalho. Por isso mesmo, na narrativa analisada condena-se a preguiça e reabilita-se o "homem preguiçoso". Ao final, a ordem é reestabelecida, pois a narrativa enaltece o trabalho e ensina que o equilíbrio familiar depende de que os membros da família exerçam seus papeis sociais de acordo com normas prévias.

Do conjunto de narrativas, das quais apresentamos apenas uma, ficam muitas perguntas. 0 que é dito? O que é silenciado? A complexidade do conto não nos permite respostas simples, mas parece certo afirmar que, ao narrar, o mestre Zé de Souza reflete em suas palavras a sua comunidade. 0 dito e o não-dito é pactuado com o coletivo, pois o narrador seleciona o que pode/deve dizer ou não, de acordo com o pacto social. Com o seu tecer, é um porta-voz, de modo a fazer com que seus ouvintes se sintam representados.

Por fim, quando os assentados do Rose apresentam seus modos de narrar, declamar poesia, entoar cantigas de roda ou reisados, dentre outras atividades culturais, o que vemos são mulheres e homens que se apropriam das armas potenciais da linguagem para promoverem a construção da comunidade, não somente nos aspectos culturais, mas em todos os modos de resistência. Ali está depositada, no arcabouço da memória, a identidade de sujeitos vindos de diversas partes e que se uniram por objetivos comuns, reconstruindo, a partir do que traziam, um teto-memória sob o qual se abrigar, como sujeitos diaspóricos, se ressignificando. Desse modo, o narrar é coletivo. $E$, enquanto coletivo, patrimônio essencial para o fortalecimento e a continuidade do grupo.

\section{Referências}

ALCOFORADO, Doralice Xavier Fernandes. A recriação do conto popular. Boitatá: Revista do GT de literatura oral e popular da ANPOLL. Londrina, UEL, n. especial Doralice Xavier Alcoforado, p.131-142, ago./2008. Disponivel em: http://www.uel.br/revista/boitata/?content=volume_especial_2008.htm. Acesso em: 03 ago. 2017.

ALCOFORADO, Doralice F. Xavier; ALBÁN, Maria del Rosário Suaréz. Contos populares brasileiros: Bahia. Recife: Fundação Joaquim Nabuco; Massangana, 2001.

BARTHES, Roland. Introdução à análise estrutural da narrativa. In: BARTHES, Roland et al. Análise estrutural da narrativa: pesquisas semiológicas. Petrópolis, RJ: Vozes, 1972. p. 19-62.

BOGO, Ademar. O MST e a cultura. Campos Elíseos, SP: MST, 2009.

BORDINI, Maria da Glória. Acervo de escritores e o descentramento da história da literatura. O Eixo e a Roda: Revista de Literatura Brasileira, Belo Horizonte: UFMG, v. 11, p. 15-23, 2005. Disponivel em: http://www.periodicos.letras.ufmg.br/index.php/o_ eixo_ea_roda/article/view/3174. Acesso em: 03 de dezembro de 2019.

BOSI, Alfredo. Dialética da colonização. São Paulo: Companhia das Letras, 1996.

BOSI, Ecléa. Memória e sociedade: lembrança de veIhos. São Paulo: Schwarcz Ltda, 2001.

BRASIL. Ministério da Agricultura, Pecuária e Abastecimento. Empresa Brasileira de Pesquisa Agropecuária - EMBRAPA. Caatinga. Disponivel em: www. embrapa.br. Acesso em: 03 abr. 2017. 
BRASIL. Instituto Brasileiro de Geografia e Estatística - IBGE. Cidades. Brasília, 2017. Disponível em: http://cidades.ibge.gov.br/. Acesso em: 28 abr. 2017.

CALDART, Roseli Salete. Pedagogia do Movimento Sem Terra. São Paulo: Expressão Popular, 2004.

CAUME, David José. A tessitura do "assentamento de reforma agrária": discursos e práticas instituintes de um espaço agenciado pelo poder. 2002. 615 f. Tese (Doutorado em Ciências Sociais) - Programa de Pós-Graduação em Ciências Sociais, Unicamp, Campinas, 2002. Disponível em: www.repositorio. unicamp.br/bitstream/REPOSIP/280936/1/Caume_ DavidJose_D.pdf. Acesso em: 11 out. 2017.

CASCUDO, Luís da Câmara. Os melhores contos de Portugal. Rio de Janeiro: Ediouro, s. d.

CASCUDO, Luís da Câmara. Contos tradicionais do Brasil. São Paulo: Global, 2004.

COSTA, Edil Silva. Ensaios de malandragem e preguiça. Curitiba: Appris, 2015.

COSTA, Edil Silva. Arquivos do pobre: considerações sobre culturas populares, memórias e narrativas. In: SANTOS, Osmar Moreira dos. (org.). Arquivos, testemunhos e pobreza no Brasil. Salvador: EDUNEB, 2016. p. 51-62.

CRUZ, Nelci Lima da. Memórias Históricas de Santa Luz: Santa Luz: [s. n.], 1996.

FERNANDES, Bernardo Maçano. A formação do MST no Brasil. Petrópolis, RJ: Vozes, 2000.

FERREIRA, Jerusa Pires. Oralidade, Mídia, Culturas Populares. Intermidias: Dossiê Jerusa Pires Ferreira, Montreal, Université de Montréal, ano 4, edição 8, 2008. Disponivel em: http://www.intermidias.com/ jerusa/. Acesso em: 05 maio 2017.

GIESBRECHT, Ralph Mennucci. Estações ferroviárias do Brasil. Disponível em: http://www.estacoesferroviarias.com.br/ba_paulistana/santaluz.htm. Acesso em: 05 maio 2017.

HAMPÂTÉ BÂ, Amadou. A tradição viva. In: KI-ZERBO, J. (org.). História Geral da África I: metodologia e pré-história da África. São Paulo: UNESCO, 1982. p. 181-218.
MEDEIROS, Leonilde Servolo de. Reforma agrária no Brasil. São Paulo, Fundação Perseu Abramo, 2003.

PEREIRA, Edisvânio do Nascimento. Narrativas sisa-

leiras: dizeres, saberes orais, fazeres e projetos culturais no Assentamento Rose, Santa Luz - BA. 2018. 159 f. Dissertação (Mestrado em Crítica Cultural) - Programa de Pós-Graduação em Crítica Cultural, Universidade do Estado da Bahia, Alagoinhas, 2018.

SANTIAGO, Gilson. História do Rose. APOCOR-Associação de Pequenos Agricultores da Comunidade Rose. Disponivel em http://apacor.blogspot. com.br/p/historia-do-rose.html. Acessado em 10/04/2017.

SANTOS, Osmar Moreira dos. A luta desarmada dos subalternos. Belo Horizonte: Editora UFMG, 2016.

SOUZA, Elizeu Clementino de. Modos de Narração e discussão da Memória: biografização, experiências e formação. In: PASSEGGI, Maria da Conceição; SOUZA, Elizeu Clementino de. (org.). (Auto) Biografia: formação, território e saberes. Natal: EDUFRN, São Paulo, 2008. p. 86-101.

SOUZA, Zé de (José Dantas de Ataídes). “João Preguiçoso": informação verbal [10 de maio de 2017]. Entrevistador: Edisvânio do Nascimento Prereira. Assentamento Rose, Santa Luz, 2017. Entrevista concedida para elaboração de Dissertação de Mestrado do entrevistador.

STEDILE, João Pedro. A reforma agrária e a luta do MST. Petrópolis, RJ: Vozes, 1997.

ZUMTHOR, Paul. A letra e a voz: a "literatura" medieval. Tradução Jerusa Pires Ferreira. São Paulo: Cia das Letras, 1993.

ZUMTHOR, Paul. Escritura e nomadismo. Tradução Jerusa Pires Ferreira. São Paulo: Ateliê Editorial, 2005.

ZUMTHOR, Paul. Introdução à Poesia Oral. Tradução Jerusa Pires Ferreira, Maria Lúcia Diniz Pochat, Maria Inês de Almeida. Belo Horizonte: Editora UFMG, 2010.

Recebido em: 23.12.2019

Revisado em: 14.05.2020 Aprovado em: 28.05.2020 
Edil Silva Costa é Doutora em Comunicação e Semiótica (PUC-São Paulo), Professora Permanente do Programa de PósGraduação em Crítica Cultural (Pós-Crítica), membro do Grupo de Pesquisa Núcleo de Tradições Orais e Patrimônio Imaterial (NUTOPIA) e do Grupo de Trabalho de Literatura Oral e Popular da Associação Nacional de Pesquisa e PósGraduação em Letras e Linguística (ANPOLL). E-mail: escosta@uneb.br

Edisvânio do Nascimento Pereira é Mestre em Crítica Cultural pelo Programa de Pós-Graduação em Crítica Cultural (UNEB), Graduado em Comunicação Social/Radialismo (UNEB) e Especialização em Inovação Social com Ênfase em Economia Solidária e Agroecologia - Instituto Federal de Educação, Ciência e Tecnologia (IF Baiano), membro do Grupo de Pesquisa Núcleo de Tradições Orais e Patrimônio Imaterial (NUTOPIA). E-mail: edisvanionascimento@yahoo.com.br 